\title{
ПСИХОЛОГИЧЕСКИЕ СРЕДСТВА ПРЕОДОЛЕНИЯ МОНОТОННЫХ ВОЗДЕЙСТВИЙ В ПРОЦЕССЕ СЛУЖЕБНОЙ ДЕЯТЕЛЬНОСТИ
}

Галаджян В. М.(Академия государственного управления РА, Ереван, Армения) williamhalajyan@gmail.com

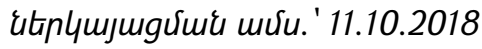
qрumpnuर्ume mर्रu.' 25.10.2018

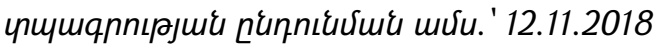

Реальные изменения условий профессиональной деятельности государственных служащих предъявляют особые требования к поддержанию адекватного состояния для выполнения работы. Цель исследования предполагала выявить психологические аспекты превентивных средств при монотонных воздействиях во время работы. В процессе исследования специально были подобраны музыкальные паузы, которые позволят преодолеть монотонные воздействий в профессиональной деятельности государственных служащих в течении рабочего дня.

Ключевые слова: служебная деятельность, психическое состояние, монотонная, работоспособность, рабочая обстановка, перцепция.

Проблема преодоления и профилактики монотонии в процессе профрессиональной деятельности вызывает особый интерес у ученых в области фризиологии, психологии, медицины, менеджмента и др. При наличии большого количества исследований и теоретических утверждений о положительном влиянии музыки на психическое состояние, тем не менее, среди них много противоречий и деталей которые требую уточнения и научной проверки. Так, например, можно с уверенностью не согласиться с гипотезой одного из исследований, согласно которой музыка играет гораздо большую роль в жизни юных и молодых людей, чем людей других возрастов, и потому активнее должна использоваться именно для саморегуляции состояний. Это предположение правомерно для определенных музыкальных стилей, которые предпочитает рассматриваемая возрастная группа. Известно, что другие люди в разных возрастах также используют музыку для улучшения настроения, получения позитивных эмоций и т.п. По результатам сравнения предпочтений прослушивания музыкальных произведений утверждается, что саморегуляция психических состояний средствами музыки осуществляется на основе переживания эмоциональных сторон музыки [2]. Этот вывод также имеет очевидный характер и не требует доказательства. Эта проблема также стала актуальной в связи трансформациями рабочей среды, т.е. всеобщей компьютеризацией делопроизводства и профессиональной коммуникации. 
На данном этапе цель исследования предполагала выявить психологические аспекты превентивных средств преодоления монотонных условий во время работы. В процессе исследования специально были подобранны музыкальные паузы, которые позволят преодолеть монотонные воздействий в профессиональной деятельности государственных служащих в течении рабочего дня. Среди современных специальностей немало таких, которые по своим функциональным характеристикам относятся к монотонным и предъявляют особые требования к профессиональным качествам сотрудника. Также особого внимания заслуживают те виды профессиональной активности, которые не зависимо от специфики связаны с необходимостью постоянного использования компьютера в течении всего рабочего дня. Данная тенденция в определенной степени относится к профессиональной деятельности государственных служащих, которые постоянно выполняют однообразные функции и связаны с электронной формой служебной коммуникации. Исследования российских психологов показали, что если в ответах на вопрос о приоритетных характеристиках государственных служащих респонденты отмечают стабильность, заработную плату, гарантии государственной службы, а их представление о государственном служащем связывается с выполнением монотонной, рутинной работы с использованием специальных прав и ресурсов [4].

Актуальность и степень исследованности проблемы подтверждены тем фактом, что армянские психологии рассматривали вопросы отбора и управления персоналом, подготовки и обучения госслужащих, компетенции и безопасность профессиональной деятельности, конфликты в и т.п. (Р. В. Агузумцян, Г. М. Аванесян, А. Б. Локян и др.) $[1,2,7]$. Теоретический анализ так же показал, что наибольшее внимание психологов направлено на специальности экстремального характера, напряжённого или связанного с рисками, а проблема поддержания работоспособности госслужащих не исследована.

Значимость связи стресса с психологическим и психофизическим функционированием человека обусловлена тем, что решение многих профессиональных задач возможно только при эффеективной адаптации человека к сложным условиям деятельности. Авторами рассматриваются такие понятия как стресс и работоспособность, а также механизмы биологической адаптации к стрессу и последствия воздействия стресса на личность сотрудника полиции. Проведено эмпирическое исследование, в рамках которого были исследованы взаимосвязи выраженности стрессового напряжения с работоспособностью сотрудников правоохранительных органов [8].

Методы преодоления или профрилактики неблагоприятного воздействия монотонной деятельности, как правило, нацелены на поддержание работоспособности сотрудников в процессе не только одного рабочего дня, но различных периодов профессиональной деятельности (недели, месяца, декады 
или года). Однако, очевидно, что если сотрудник имеет способность или владеет специальными приемами поддержания работоспособности в течении одного рабочего дня, то он избежит негативного воздействия кумулятивного механизма утомляемости. В связи с этим подчёркивается значимость внедрения специальных методов, которые позволят сотруднику в течении одного дня преодолеть воздействие монотонных и стрессогенных факторов на фризическое и психическое состояние. Как правило, подобные методы включают совмещение или раздельное применение фризических и психологических упражнений, среди которых особое внимание уделяется музыкальному сопровождению. Конкретные данные по этой проблеме представлены в исследовании, посвященном особенностям влияния музыки на работоспособность и психоэмоциональное состояние человека, в которой этот процесс рассмотрен в комплексе с физической активностью. Так, например, Л. В. Шейко отмечает, что монотонность плавания является одним из весьма существенных факторов, препятствующих положительному отношению занимающегося к тренировочным нагрузкам, т.к. может способствовать снижению эффрективности тренировочного процесса, вызывая у него нарастающее пресыщение, лишая радости от двигательной активности. Для преодоления данного явления предлагается использовать музыкальное сопровождение, которое создаёт наиболее благоприятные фризиологические и психоэмоциональные условия для оптимальной реализации потенциальных возможностей занимающегося, для защиты его от отрицательного влияния стрессов, время от времени возникающих в непростых условиях современной жизни [11; с.340].

В учебных пособиях по психологии и психофизиологии в процессе внимания выделяется наиболее важная функция, которая реагирует на состояния утомления, стресса и монотонии. При этих состояниях наблюдается прогрессирующее снижение активности внимания. Вместе с тем, высокая мотивация на деятельность оказывает мощное компенсирующее влияние на сохранность внимания даже в самых неблагоприятных условиях $[6,10]$. Помимо высокой мотивации, которая имеет первостепенное значение, поддержанию адекватной профессиограмме работоспособности и профилактики профессиональной деформации может способствовать специально разработанная методика музыкального воздействия. Особенности произвольной регуляции внимания в процессе профессиональной деятельности досконально представлены в исследованиях Е. П. Ильина (2008). Автор, характеризуя эти особенности поведения человека в процессе работы, указывает на необходимость применения психологических средств профилактики профессиональной деформации [5].

Многие авторы предлагают целый ряд упражнений по переключению внимания, которые помогают в процессе однообразной деятельности преодолеть утомляемость. Так, например, группа авторов разработали целый 
комплекс упражнений для различных видов профессиональной деятельности [9]. Предложенные упражнения подобранны так, чтоб для их правильного выполнения необходимо сосредоточить внимание. Подобную фуннццию может выполнять и кратковременные музыкальные паузы, которые способствуют как концентрации, так и переключению внимания.

В литературных источниках, посвященных разработке проблем музыкальной психологии, можно выделить две наиболее крупные области исследования: изучение избирательности в музыкальной сфере, рассматриваемое в рамках восприятия и предпочтения музыки разных жанров, и изучение влияния музыки на физиологические функции, психическое состояние и деятельность человека. При исследовании музыкальных предпочтений внимание сосредотачивается на выявлении факторов, определяющих избирательность восприятия музыки. Чем более выражено соответствие музыки неосознаваемым потребностям, тем эфффективней является воздействие [3].

Профессиональная деятельность публичных служащих (на примере публичных служащих РА) по характерологическим особенностям может быть отнесена к монотонной [7]. Следовательно, возникает необходимость применения специальных и, в частности, методик музыкального воздействия для поддержания работоспособности сотрудников. Как правило, кратковременные музыкальные отрывки можно внедрить во время обеденного перерыва и при специальных кратковременных паузах через определенное время, которое должно соответствовать определенному ритму служебной занятости и конкретной профессиональной среде.

В соответствии с целью работы на предварительном этапе исследования на основе экспертного опроса (психологи эксперты в области психорегуляции, всего 10 чел.) из 20-ти было отобрано четыре музыкальных клипа следующего характера: нейтральный/космический, романтический/классический, национальный/восточный и ритмичный/рок музыка. После прослушивания в лабораторных условиях, в которых участвовали 30 госслужащих, был проведен опрос для оценки предпочтений и полученных ассоциаций. Контент анализ ассоциаций и ранжирование предпочтений позволили отобрать два музыкальных клипа, а именно, восточный и ритмичный.

Анализ полученных оценок оба варианта имели наиболее позитивные ассоциации, а первый, снимает напряжение, а второй позволяет переключить внимание. Следовательно, отобранные музыкальные клипы целесообразно предложить для прослушивания в разное время рабочего дня (в обеденный перерыв, в середине первой и второй половине дня). Далее предусмотрен моделирующий эксперимент для выявления индивидуальной предрасположенности и последующих рекомендаций выбора музыкальных фрагментов для сотрудников. 


\section{Литература}

1. Аванесян Г. М. Стратегия совершенствования психологических критериев отбора сотрудников//Научный журнал "Wisdom”, № 1 (1) / 2013. C. 164-167

2. Гильманов С. А. Роль музыки в саморегуляции психических состояний// Материалы Первой Всероссийской научно-практической конференции. Казанский государственный университет, 13-15 ноября 2008 г. Часть І. Казань: 3АО «Новое знание», 2008. с. 230-234.

3. Дергаева И. А. Комплексное исследование восприятия и психологического воздействия музыки. Автореф. кандидата психол. наук, 19.00.01, Ярославль, 2005

4. Иванова Н. Л., Подольский Д. А. Гарантии государственных гражданских служащих как элемент современной кадровой политики// Вопросы государственного и муниципального управления, №1, 2017, С.173-175

5. Ильин Е. П. Дифференциальная психология профессиональной деятельности. СПб.: Питер, 2008. 432 с.

6. Карпов, А. В. Психология труда: учебник для бакалавров/2-е изд. М.: Издво Юрайт, 2013. - 350 с.

7. Локян А. Б. Концептуальные основы структурирования системы психологической подготовки управленца публичной службы Республики Армения. Диссер. док. психол. наук. Ереван, 2016

8. Николаева Н. В., Коноплева И. Н. Выраженность стрессового напряжения и работоспособность сотрудников правоохранительных органов/ Психология и право. МГППУ, N2, 2014, с.87-100

9. Профилактика стрессового состояния работников при различных видах профессиональной деятельности/ Метод. рекомендации, М.: 2008// https://meganorm.ru/ Data2/1/4293830/4293830643.htm

10.Психология труда. Конспект лекций. Григорьева М. В. М.: Высшее образование, 2006. - 192 с.

11. Шейко Л. В. Влияние музыки на работоспособность и психоэмоциональное состояние людей 40-60 лет в процессе занятий оздоровительным плаванием// Сучасні проблеми здоров'я та здорового способу життя у фрізкультурній освіті. Вісник №129, Том III. с.339-344 


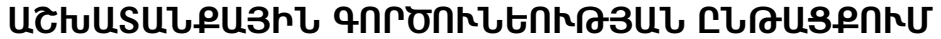

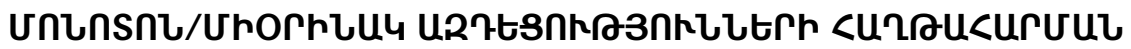

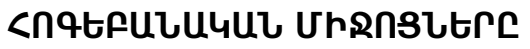

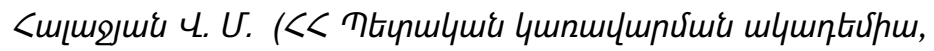
tpliши, <щјмичмия)

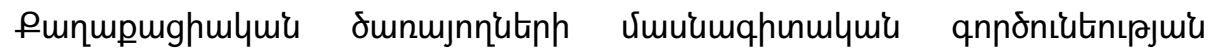

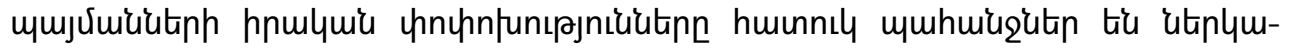

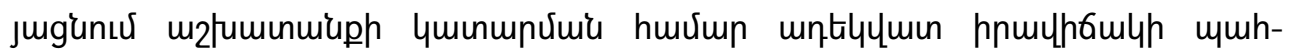

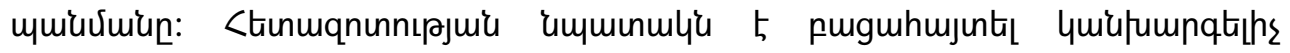

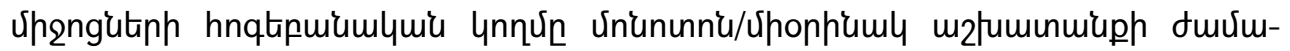

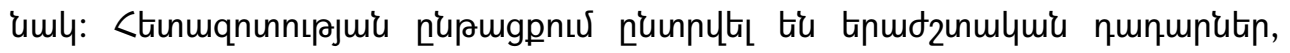

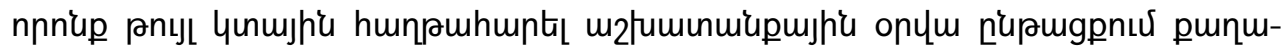

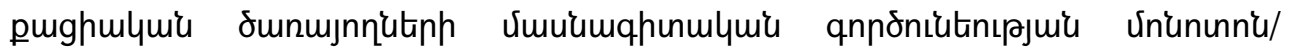
uhonhumuly mqntignıpjnıuutunn:

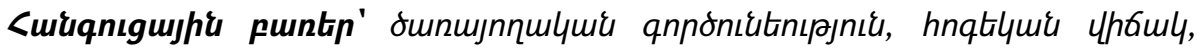

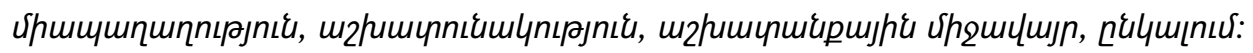

\section{PSYCHOLOGICAL MEANS OF OVERCOMING MONOTONOUS INFLUENCES DURING PERFORMANCE}

Halajyan W. M. (Academy of Public Administration of RA, Yerevan, Armenia)

Real changes in the conditions of professional activity of civil servants impose special requirements on the maintenance of an adequate state for the performance of work. The purpose of the study was to reveal the psychological aspects of preventive methods with monotonic effects during professional performance. In the process of the study, musical pauses were specially selected that would allow to overcome the monotonous influences in the professional activity of civil servants during the working day.

Keywords: performance, mental state, monotonous, working capacity, working environment, perception. 